\title{
From Appraisal to Emotion: Differences Among Unpleasant Feelings ${ }^{1}$
}

\author{
Phoebe C. Ellsworth ${ }^{2}$ and Craig A. Smith ${ }^{3}$ \\ Stanford University
}

Recent research has indicated strong relations between people's appraisals of their circumstances and their emotional states. The present study examined these relations across a range of unpleasant situations in which subjects experienced complex emotional blends. Subjects recalled unpleasant experiences from their pasts that were associated with particular appraisals and described their appraisals and emotions during these experiences. Situations defined by particular appraisals along the human agency or situational control dimensions were reliably associated with different levels of anger, sadness, and guilt, as predicted. However, predicted differences in emotion were not observed for situations selected for appraisals along the certainty or attention dimensions. Most subjects reported experiencing blends of two or more emotions, and correlation/regression analyses indicated that even in the context of these blends, patterns of appraisal similar to those observed previously (Smith \& Ellsworth, 1985, 1987) characterized the experience of the individual emotions. The regressions further indicated that appraisals along some dimensions were more important to the experience of particular emotions than were appraisals along other dimensions. These central appraisals are compared with the adaptive functions their associated emotions are believed to serve, and the implications of these findings are discussed.

\footnotetext{
This research was supported in part by a Stanford University graduate fellowship and in part by a National Institute of Mental Health training grant to Craig Smith. Part of the writing was done while Phoebe Ellsworth was a fellow at the Center for Advanced Study in the Behavioral Sciences, supported by the John D. and Catherine T. MacArthur Foundation and by the James McKeen Cattell Fund.

${ }^{2}$ Address all correspondence to Phoebe C. Elsworth, Research Center for Group Dynamics, ISR, University of Michigan, Ann Arbor, Michigan 48106-1248.

${ }^{3}$ Craig A. Smith is now at Peabody College, Vanderbilt University.
} 
In order to maneuver successfully in its environment, an organism must be able to sense and respond to events that are relevant to its needs. In lower organisms, the sensing is thoughtless and the response is automatic. Higher up the phylogenetic scale, organisms experience a much wider variety of needs and goals, and instead of merely sensing environmental events, they interpret them. Interpretations of events that are particularly relevant to such needs lead to emotions. Emotions, in turn, motivate the organism to respond to its environment, but allow an adaptive flexibility of response that is not available to organisms that rely on instinct.

A growing number of theorists from various disciplines, following the leads of Darwin (1872/1965), James (1890/1950), Leeper (1948), and Tomkins (1963), have converged on this general view of the adaptive nature of emotions and their role in human experience (Arnold, 1960; D'Andrade, 1981; Frijda, 1986; Lazarus, 1982; Roseman, 1984; Scherer, 1984; Smith \& Ellsworth, 1985, 1987). Our own recent research has been devoted to exploring some of the implications of this point of view. In particular, we have tried to go beyond the general statement that cognition (or appraisal, or perception, or interpretation, or, more neutrally, information processing) is an important component of emotion, and to ask what kinds of perceptions are most important in differentiating more emotional from less emotional experience, and in differentiating one emotion from another.

In our initial study (Smith \& Ellsworth, 1985) we proposed eight appraisal dimensions that we believed to be important in differentiating emotional experience: Pleasantness, Anticipated Effort, Attentional Activity, Certainty, Responsibility, Control, Legitimacy, and Perceived Obstacle.

In that study we asked subjects to recall a time when they had experienced a particular emotion, and then to rate their appraisals of that situation along our proposed dimensions. We found that subjects had reliably used six orthogonal dimensions in their ratings. Four of these corresponded to the proposed dimensions of pleasantness, anticipated effort, attentional activity, and certainty. The remaining two were combinations of the proposed responsibility and control dimensions. The first dimension, human agency, reflected the perception that oneself or some other person was responsible for, and/or in control of, the situation. The second dimension, situational control, reflected the perception of the situation as being controlled by any human being, or by impersonal circumstances.

\section{CENTRAL AND PERIPHERAL DIMENSIONS}

Almost every one of the 15 emotions was characterized by a distinctive combination of appraisals ${ }^{4}$ However, there were some indications that cer-

${ }^{4}$ Sharhe and guilt exhibited highly similar patterns of appraisals, as did anger and contempt. 
tain appraisals are more important in the experience of some emotions than others, and more important in differentiating between some classes of emotion than other classes. To take the most obvious example, appraisals of the pleasantness of the situation accounted for the largest proportion of the variance when all 15 emotions were considered together, but this dimension was relatively unimportant in differentiating among either the positive or negative emotions. Apparently, once the situation had been appraised as basically good or bad, other kinds of information determine which particular emotions a person feels. The appraisal of agency was most important in differentiating among the negative emotions. Shame and guilt were distinguished by appraisals of self-agency; anger, contempt, and disgust by appraisals of other-agency. Sadness and, to a lesser extent, fear, were distinguished by strong appraisals that impersonal circumstances were controlling the situation. In addition, fear was distinguished by a high level of uncertainty, frustration by a high level of attention, and boredom and disgust by particularly low levels of attention.

Although the theory is a theory of emotional experience, the first study was a study of remembered emotions and appraisals. Our next step was to examine the relations between appraisals and emotions during two actual emotional experiences - the anticipation of a midterm exam and the receipt of the exam grades (Smith \& Ellsworth, 1987). A majority of the students reported that they experienced complex blends of two or more emotions, particularly before the exam (see also Folkman \& Lazarus, 1985; Izard, 1972; Schwartz \& Weinberger, 1980, on the pervasiveness of mixed emotions in natural settings). Nonetheless, very strong, clear, and differentiated patterns of appraisal were associated with the experience of specific emotions, whether they were pure or mixed.

The patterns of appraisal for each emotion were very similar to those in the first study, but not identical. In general, the complex, immediate emotions of the midterm study were characterized by fewer appraisals than the pure, remembered emotions of the original study. In the original study, for example, anger was associated with appraisals of unpleasantness, otheragency, effort, and moderate certainty. In the midterm study, unpleasantness and other-agency were still highly characteristic of anger, but effort and certainty were not.

These findings suggest that not all of the appraisals subjects recalled for "pure" experiences of single emotions are equally important. That is, although a given set of appraisals may be associated with typical instances of a particular emotion, some of these appraisals (such as high certainty and high effort in anger) may be subsidiary and often (e.g., during blending) will not be strongly associated with the emotion. In contrast, other appraisals (such as other-agency in anger) may be so vital to the experience of an emotion as to be considered diagnostic. 


\section{THE PRESENT RESEARCH: FROM APPRAISALS TO EMOTIONS}

The present research was designed to explore certain appraisals in detail, in order to shed some light on inconsistencies between the two studies and to explore the idea that for any given emotion, some appraisals are more central than others. In our previous research we have begun with an emotional situation and then asked subjects about their accompanying appraisals. In order to examine specific combinations of appraisals in detail (and to provide some convergent validity), we now reversed this procedure: We asked people to recall situations that they had appraised in certain ways, and then asked them what they felt. Thus, instead of examining the patterns of appraisal associated with particular emotions, we examined the patterns of emotion associated with particular appraisals. This approach also allowed us to examine the relation between appraisals and emotions in the context of blends across a much broader range of emotional experience than was possible in the exam study. Because no emotional terms were used in defining the experience, we expected that most subjects would report experiences in which they had felt several different emotions simultaneously (Schwartz \& Weinberger, 1980).

Investigation 1: Agency and Legitimacy. In our initial study (Smith \& Ellsworth, 1985), the perception of agency was fundamental in differentiating among the unpleasant emotions, particularly anger, guilt, and sadness. In the exam study, however, the results were ambiguous for sadness and guilt. The dimension of situational control, central to the experience of sadness in the first study, did not emerge, presumably because none of the students reported feeling particularly sad. Guilt was not reliably associated with selfagency, possibly owing to the constraints of the setting (see Smith \& Ellsworth, 1987). Therefore, a goal of this first investigation was to test whether the characteristic relations between appraisals of agency and the experience of anger, guilt, and sadness, discovered in the initial study, would be observed during emotional blends when an adequate range of experience was sampled.

Further, in our initial formulation of the theory we had postulated that responsibility for bringing about a situation, control of the situation as it developed, and the fairness or legitimacy of the outcome would all emerge as separate dimensions, because logically they are separate. One may be responsible for bringing about a situation that quickly develops beyond one's capacity to control it (for example, by forgetting to set the brakes on a San Francisco hill, or by shouting "Go, Yankees" in Fenway Park); one may also be able to assume control of a situation brought about by someone else (for example, by responding to a challenge). We had postulated legitimacy (perceived fairness) as an important dimension in the emotion of anger (see also, Roseman, 1984), distinct from either responsibility or control. However, our subjects have so far failed to distinguish so finely among dimensions; they 
have consistently collapsed appraisals of responsibility and control into a single dimension of agency, and in unpleasant situations appraisals of otheragency and unfairness seem to be functionally synonymous. By asking subjects about situations defined by emotions rather than appraisals we may have biased our sample of emotional experiences toward those in which responsibility, control, and legitimacy were confounded. In the present study, we asked about these appraisals separately, hoping to unconfound them and discover differences in their contributions to emotional experience not discernible by our previous methods.

Investigation 2: Certainty. The second investigation focused on the certainty dimension. The theory predicts that intense uncertainty should differentiate fear from the other negative emotions, and this was the case in our initial study (Smith \& Ellsworth, 1985). However, the relation between fear and uncertainty in the exam context was weaker than we predicted (Smith \& Ellsworth, 1987). In the present study, we wanted to examine whether this result was peculiar to the situational constraints of that study, or whether the appraisal of uncertainty is less central to the experience of fear than we had believed.

Investigation 3: Attention. The third investigation was devoted to the dimension of attentional activity and was designed to explore our initial finding that this dimension was important in differentiating boredom and disgust (low desire to attend) from the other unpleasant emotions, and especially from frustration (high attentional activity). Because none of these emotions was common in the exam study (Smith \& Ellsworth, 1987), this investigation represents the first test of whether they are differentiated by appraisals of attention in the context of blends.

\section{METHOD}

\section{Subjects and Overview of Procedure}

Subjects were 240 Stanford University undergraduates, ${ }^{5}$ who participated in the experiment as part of an introductory psychology course requirement. Subjects were asked to recall and describe (in writing) an unpleasant emotional experience characterized by a particular situational appraisal (e.g., "describe a time when you felt that events were being determined by circumstances beyond anyone's control"). They then rated their experience along all of the appraisal dimensions and finally indicated what emotions they felt

\footnotetext{
${ }^{5}$ An additional 5 subjects were not included in the sample because they either reported being unable to recall an appropriate experience or failed to complete substantial portions of their questionnaires.
} 
at the time. The subjects were run in small groups. Each subject was randomly assigned to one of 10 appraisal conditions with the constraint that, as much as possible, each condition be represented equally often within each session. The experiment required approximately 15 minutes and was administered as one of several unrelated short experiments to be completed during the experimental hour.

\section{Appraisal Conditions}

Investigation 1: Agency and Legitimacy. This was the largest of the investigations. In it we compared six appraisals along dimensions related to responsibility and control. Four of these appraisals, "self-responsibility," "selfcontrol," "other-responsibility," and "other-control," represented outcomes along the human agency dimension, which we had found to be especially important in differentiating between unpleasant emotions such as anger and guilt. We included these four cells in an attempt to discover possible differences between appraisals of responsibility and control, and to replicate the findings for self- and other agency.

These first four appraisals all represent some form of human agency and therefore fall on the "human agent" pole of the situational control dimension. The fifth appraisal, "situational control," falls on the opposite end of this dimension and has previously emerged as a central appraisal differentiating the experience of sadness from other unpleasant states.

The sixth appraisal, "unfair," we included to reexamine the previously observed close relation between appraisals of unfairness and other-agency by testing the extent to which situations initially defined by the appraisal of either unfairness or other-agency would be associated with similar patterns of emotion.

Investigation 2: Certainty. This investigation consisted of two appraisals, "certain" and "uncertain." On the basis of our past research we predicted that this dimension would be important in differentiating fear (uncertain) from most of the other unpleasant emotions.

Investigation 3: Attention. This investigation consisted of two appraisals, "attend" and "shut out." In light of the earlier findings we predicted that this dimension would be important for differentiating boredom and disgust (low attentional activity) from the other unpleasant emotions, and especially from frustration (high attentional activity).

\section{General Procedure}

On the first page of the questionnaire we asked the subject to write a description of a past emotional experience associated with one of the 10 
different appraisals. For example, the instructions for the "self-responsibility" appraisal were as follows:

Please try to recall a past unpleasant emotional experience when you felt responsible for what was happening in the situation. Try and remember as vividly as you can what this past situation was like: Try to think back and reexperience the emotions that you were feeling during this experience. Think of what happened in this situation, why you felt responsible, and what it felt like to be in this particular situation.... Briefly, please describe this past unpleasant situation where you felt responsible for what was happening. What happened, and why did you feel that you were responsible?

Corresponding instructions for the other appraisals were as follows:

Other-responsibility: "when you felt that someone else was responsible for what was happening."

Self-control: "when you felt that you were in control of what was happening."

Other control: "when you felt that someone else was in control of what was happening."

Situational-control: "when you felt that the events were being determined by circumstances beyond anyone's control."

Unfair: "when you felt that something unfair happened to you."

Certain: "when you were certain about what was happening in the situation."

Uncertain: "when you were uncertain about what was happening in the situation."

Attend: "whey you felt a need to pay close attention to what was happening in the situation."

Shut out: "when you felt a need to put what was happening out of your mind."

Subjects described events that were, if anything, more emotional and important than the events they described orally in our earlier research, although the descriptions were briefer. For example, the experiences included getting arrested for drunk driving, wrecking the parents' car, learning that a parent had cancer, witnessing a roommate get seriously injured in a football game, having an abortion, lying about qualifications in order to get a job, the suicide of a friend, breaking up with a boyfriend or girlfriend (many instances), deaths of close friends and relatives, and parents getting divorced or separated.

\section{Measures}

After describing the experience, the subject completed two questionnaires, one measuring appraisals and the other emotions. The emotion questionnaire always came after the appraisal questionnaire. With minor modifications these were the same questionnaires used by Smith and Ellsworth (1987).

${ }^{6}$ For this appraisal we did not specify that the emotional experience had to be unpleasant, but it always was. 
Appraisal Questionnaire. This questionnaire consisted of 1911 -point scales designed to measure the dimensions of pleasantness, anticipated effort, attentional activity, certainty, responsibility, control, legitimacy, perceived obstacle (Smith \& Ellsworth, 1985), and situational importance (Smith \& Ellsworth, 1987). Table I shows the wordings of the items. The subject was instructed to answer each question by circling "the number that best describes how you felt while you were actually experiencing this past situation (not how you felt either before or after the situation occurred)."

Emotion Questionnaire. On this questionnaire the subject was asked to rate on scales ranging from 1 (not at all) to 9 (extremely) the extent to which each of 25 emotional adjectives (listed in Table III) described how he or she was feeling while "actually experiencing this past situation." The 25 adjectives were the same ones used by Smith and Ellsworth (1987) and were selected to measure up to 16 potentially distinct emotions, 8 of which were unpleasant and 8 pleasant.

\section{RESULTS}

\section{Overview}

After estimating values for missing data and reducing the data, we used two complementary analytic strategies to examine the relations between particular appraisals and the experience of particular emotions. One set of analyses examined differences in the emotions felt during experiences selected because they were associated with specific appraisals along a particular dimension, or a set of closely related dimensions. In these analyses, analysis of variance (ANOVA) techniques were used to compare the emotions experienced in the various cells of each of the three investigations. Finally, after assessing the degree of emotional blending reported by individual subjects in all three investigations, a series of correlation/regression analyses was conducted to examine the characteristic patterns of appraisal, across all appraisal dimensions, associated with the experience of specific emotions.

\section{Data Estimation}

Because the multivariate techniques employed in this study require complete data sets, we estimated values for missing data points. Across the 10 experimental conditions, $44(0.96 \%)$ of the appraisal data points, and 17 $(0.28 \%)$ of the emotion data points were missing. The distribution of these points suggested that they were largely random failures to respond to individual items. Estimates for the missing values were computed using a two-step regression procedure. Separate analyses were run for the appraisal and emo- 
Table I. Internal Structure of the Nine Recovered Appraisal Scales

1. Pleasantness $\quad M=2.34 \quad S D=1.68 \quad \alpha=.77$

Pleasant-How pleasant or unpleasant was it to be in this situation?

Enjoy-How enjoyable or unenjoyable was it to be in this situation?

2. Anticipated effort $\quad M=7.82 \quad S D=2.23 \quad \alpha=.73$

Effort-How much effort (mental or physical) did you feel

the need to expend in this situation?

Exert-To what extent did you feel that you needed to exert yourself in order to deal with this situation?

3. Attentional activity $M=7.05 \quad S D=2.64 \quad \alpha=.73$

Attend-Think about what was happening in this situation.

To what extent did you try to devote your attention to what was going on, or to think about something else?

Think - Think about what was happening in this situation. To what extent did you try to think about these things further, or to put them out of your mind?

4. Certainty $M=6.83 \quad S D=2.76 \quad \alpha=.77$

Sure-How sure were you about what was happening in this situation?

Understand - When you were in this situation, how well did you understand what was happening around you?

5. Human agency $M=6.93 \quad S D=2.41 \quad \alpha=.82$

Other-responsibility - How responsible did you think someone or something other than yourself was for having brought about the events that were occurring in this situation?

Self-responsibility ${ }^{a}-$ How responsible did you feel for having brought about the events that were occurring in this situation?

Other-control - To what extent did you feel that someone other than yourself was controlling what was happening in this situation?

Self-control ${ }^{a}-$ To what extent did you feel that you could influence what was happening in this situation?

Cheated - To what extent did you feel cheated or wronged in this situation?

Fair ${ }^{a}$ - How fair did you think what happened to you in this situation was?

6. Situational control $M=5.11 \quad S D=3.31$

Situational control-To what extent did you feel that circumstances beyond anyone's control determined what was happening in this situation?

7. Perceived obstacle $M=7.81 \quad S D=2.24 \quad \alpha=.69$

Problem - Think about what you wanted in this situation. To what extent did you feel that there were problems that had to be solved before you could get what you wanted?

Obstacle-Think about what you wanted in this situation. To what extent did you feel there were obstacies standing in the path between you and getting what you wanted?

8. Importance $M=9.24 \quad S D=2.07$

Importance-How important was what was happening in this situation to you?

9. Predictability $M=5.18 \quad S D=3.08$

Predict - When you were in this situation, how well could you predict what was going to happen?

${ }^{a}$ The scores for this item were reversed in computing the scale scores. 
tion data, and the entire data set, including the 61 estimated values, was employed in all subsequent analyses.

\section{Recovery of the Appraisal and Emotion Scales}

Both the appraisal and emotion data were reduced to final sets of scales by examining the a priori scales designed into the questionnaires, and using factor analysis to examine whether any of the a priori scales within a set were redundant and could be combined. On the basis of these analyses, scale scores were computed for each subject by combining (with unit weight) the items loading on a scale and taking the mean (to convert the scale back to original units).

Appraisal Dimensions. The reduction procedure resulted in nine appraisal scales. The items contributing to each of these scales, and their overall means, standard deviations, and internal consistencies ( $\alpha$ 's), are listed in Table I. In general, these scales correspond very closely to the dimensions that were recovered in our previous work (Smith \& Ellsworth, 1985, 1987). Each of the six dimensions recovered in the original study (Smith \& Ellsworth, 1985 ) is clearly represented: pleasantness, anticipated effort, attentional tivity, certainty, human agency, and situational control. Two of the remaining three scales correspond to dimensions observed in the exam study (Smith \& Ellsworth, 1987): perceived obstacle and importance. The remaining scale represents a new, distinct certainty dimension, predictability. In our initial study we suggested that the certainty dimension needed further differentiation, and the present study suggests two distinct facets of certainty: certainty about what is currently happening, and certainty about the outcome of the situation. The present study resembled the initial study, but not the exam study, in that the two legitimacy items failed to define a separate dimension but instead loaded highly on the human agency dimension. Further, these items were as highly correlated with the four items intended to measure agency (average $r=.40$ ) as the four agency items were intercorrelated with each other (average $r=.41$ ). Thus, as in the initial study, when unpleasant events were recalled, appraisals of unfairness were closely associated with those of other-agency.

Examination of the overall scale means indicates that, as intended, subjects described events that they had found to be very unpleasant and, additionally, to be very important, involving many or large goal-obstacles, and requiring high levels of effort.

Intercorrelations Among the Appraisal Scales. The scales constructed in this study are not artificially constrained to be orthogonal. Thus, an examination of the intercorrelations among the scales permits an examination 
of the potential interrelations among the underlying dimensions. The intercorrelations among the appraisal scales are presented in Table II. Many of the significant correlations are familiar from previous research: The correlation of importance with high levels of attention and effort; the correlation of other-agency with perceptions of uncertainty, unpleasantness, and major obstacles; the correlation of perceived obstacles with high effort and unpleasantness; and the correlations of unpleasantness and effort. These stable relations may reflect general properties of the appraisal process, owing either to constraints in the structure of emotional situations or to constraints in the appraisal process itself. In future research a systematic examination of these stable interrelations may be useful in identifying the nature of such constraints and their implications for the appraisal process.

Emotion Scales. The reduction procedure resulted in 12 emotion scales, 6 representing unpleasant emotions and 6 representing pleasant ones. The items contributing to each of these scales, and their overall means, standard deviations, and internal consistencies ( $\alpha$ 's) are listed in Table III. The 6 unpleasant emotion scales correspond to the a priori scales of anger, guilt, sadness, fear, resignation, and boredom. The one discrepancy between these scales and the a priori ones was that, although anger, disgust, and frustration were conceptualized as distinct emotions (and were quite distinct in our original study, Smith \& Ellsworth, 1985), the scales intended to measure frustration and disgust were both found to load highly on the anger factor in the factor analyses and thus were subsumed by the anger scale. Four of the 6 pleasant emotion scales corresponded exactly to the a priori scales intended to measure hope, surprise, interest, and relief. Additionally, the challenged item combined with the two items designed to measure pride to yield a three-

Table II. Intercorrelations Among the Appraisal Scales ${ }^{g}$

\begin{tabular}{|c|c|c|c|c|c|c|c|c|}
\hline Appraisal & 2 & 3 & 4 & 5 & 6 & 7 & 8 & 9 \\
\hline 1 Agency ${ }^{a}$ & - & $-.18^{e}$ & $-.14^{d}$ & - & $-.18^{e}$ & - & $.15^{d}$ & .10 \\
\hline 2 Sit. control ${ }^{b}$ & & $-.20^{e}$ & - & - & $-.14^{d}$ & - & .11 & $.18^{e}$ \\
\hline 3 Certainty & & & $.25^{f}$ & .10 & - & - & - & - \\
\hline 4 Predict $^{*}$ & & & & - & - & - & $.13^{d}$ & - \\
\hline 5 Attention & & & & & - & $.27^{f}$ & - & $.25^{f}$ \\
\hline 6 Pleasantness & & & & & & $-.24^{f}$ & $-.18^{e}$ & $.44^{f}$ \\
\hline 7 Effort & & & & & & & $.22^{f}$ & $.47^{f}$ \\
\hline 8 Obstacle & & & & & & & & $.34^{f}$ \\
\hline 9 Importance & & & & & & & & - \\
\hline
\end{tabular}

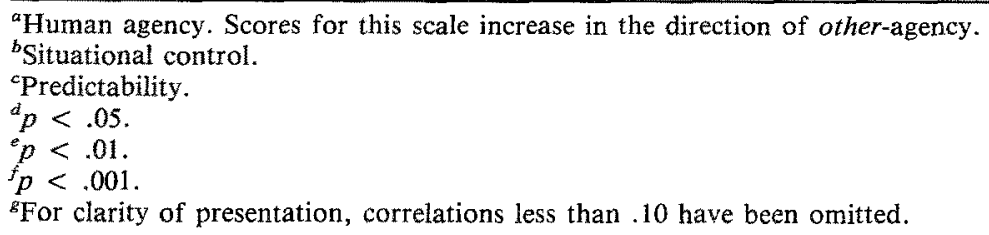


Table III. Internal Structure of the 12 Recovered Emotion Scales ${ }^{a}$

\begin{tabular}{|c|c|c|c|c|}
\hline 1. & Anger & $M=4.98$ & $S D=2.12$ & $\alpha=.88$ \\
\hline & Angry, scornful, conte & emptuous, res & ntful, disgusted & 1, frustrated \\
\hline 2. & $\begin{array}{l}\text { Guilt } \\
\text { Guilty, ashamed }\end{array}$ & $M=3.53$ & $S D=2.44$ & $\alpha=.77$ \\
\hline 3. & $\begin{array}{l}\text { Sadness } \\
\text { Sad }\end{array}$ & $M=5.89$ & $S D=2.67$ & \\
\hline 4. & $\begin{array}{l}\text { Fear } \\
\text { Nervous, afraid }\end{array}$ & $M=5.20$ & $S D=2.43$ & $\alpha=.72$ \\
\hline 5. & $\begin{array}{l}\text { Resignation } \\
\text { Resigned }\end{array}$ & $M=3.53$ & $S D=2.45$ & \\
\hline 6. & $\begin{array}{l}\text { Hope } \\
\text { Hopeful, expectant }\end{array}$ & $M=3.50$ & $S D=2.18$ & $\alpha=.74$ \\
\hline 7. & $\begin{array}{l}\text { Challenge/Pride } \\
\text { Challenged, confiden }\end{array}$ & $\begin{array}{l}M=3.06 \\
t, \text { proud }\end{array}$ & $S D=1.75$ & $\alpha=.66$ \\
\hline 8. & $\begin{array}{l}\text { Surprise } \\
\text { Surprised }\end{array}$ & $M=4.93$ & $S D=2.62$ & \\
\hline 9. & $\begin{array}{l}\text { Interest } \\
\text { Interested }\end{array}$ & $M=4.85$ & $S D=2.93$ & \\
\hline 10. & $\begin{array}{l}\text { Happiness } \\
\text { Happy, elated, amuse }\end{array}$ & $\underset{\text { ed }}{M}=1.43$ & $S D=0.89$ & $\alpha=.68$ \\
\hline 11. & $\begin{array}{l}\text { Boredom } \\
\text { Bored, apathetic }\end{array}$ & $M=1.89$ & $S D=1.37$ & $\alpha=.59$ \\
\hline 12. & $\begin{array}{l}\text { Relief } \\
\text { Relieved }\end{array}$ & $M=1.80$ & $S D=1.73$ & \\
\hline
\end{tabular}

The adjectives listed under each scale name are the emotional adjectives that contributed to that scale with unit weighting. The last three scales (Happiness, Boredom, and Relief) were not retained for further analysis. See text for explanation.

item challenge/pride scale, and the amused item combined with the two items intended to measure happiness to yield a three-item happiness scale. Of these 12 scales, happiness, relief, and boredom were dropped from further consideration because they each had means and standard deviations less than 2 (on scales ranging from 1 to 9 ), indicating that the subjects in this study almost never reported experiencing them.

Intercorrelations Among the Emotion Scales. As with the appraisal scales, the emotion scales were not necessarily orthogonal, and an examination of the intercorrelations among them offers a preliminary view of the emotional blending in the situation the subjects described. Table IV reveals a number of significant correlations, providing support for the claim that under many conditions emotions occur in complex blends (e.g., Folkman \& Lazarus, 1985; Izard, 1972; Smith \& Ellsworth, 1987; Schwartz \& Weinberger, 1980). For instance, sadness and fear were very likely to cooccur, as were hope, interest, and challenge/pride. Interestingly, with the exception of resignation and challenge/pride, which are negatively correlated, there is a general absence of significant negative correlations among the emotions. 
Table IV. Intercorrelations Among the Emotion Scales ${ }^{\alpha}$

\begin{tabular}{lcccccccc}
\hline \multicolumn{1}{c}{ Emotion } & 2 & 3 & 4 & 5 & 6 & 7 & 8 & 9 \\
\hline 1 Anger & - & $.15^{c}$ & - & .12 & -.11 & .11 & $.20^{d}$ & - \\
2 Guilt & & - & $.23^{e}$ & - & - & -.11 & - & - \\
3 Sadness & & & $.34^{e}$ & $.15^{c}$ & - & -.12 & - & $.13^{c}$ \\
4 Fear & & & & - & $.26^{e}$ & - & $.15^{c}$ & $.21^{e}$ \\
5 Resignation & & & & & - & $-.14^{c}$ & - & - \\
6 Hope & & & & & & $.44^{e}$ & - & $.34^{e}$ \\
7 Challenge & & & & & & & - & $.25^{e}$ \\
8 Surprise & & & & & & & $.27^{e}$ \\
9 Interest & & & & & & & & - \\
\hline
\end{tabular}

${ }^{a}$ For clarity of presentation, correlations less than .10 have been omitted.

${ }^{b}$ Challenge/Pride.

${ }^{c} p<.05$.

${ }^{d} p<.01$.

${ }^{e} p<.001$.

This result indicates that, in general, the presence of any particular emotion did not preclude the experience of most of the other emotions.

\section{Investigation 1: Agency and Legitimacy}

Analytic Strategy. The six cells constituting this investigation were selected to investigate differences in the emotions associated with appraisals along the agency dimensions. These differences were examined using six a priori contrasts designed to examine specific questions of theoretical interest (Rosenthal \& Rosnow, 1985). The first two comparisons were designed to replicate the previous findings. The first contrasted the two self-agency cells (selfresponsibility and self-control) with the two other-agency cells (otherresponsibility and other-control). We predicted that guilt would be experienced in the self-agency cells, and anger in the other-agency cells. The second contrast, orthogonal to the first, pitted the situational control cell against all four human agency cells. We expected relatively high levels of sadness, and relatively low levels of anger and guilt, to be associated with appraisals of situational control.

The four remaining contrasts were more exploratory. Two of these, which were orthogonal to the above two contrasts and to each other, were used to investigate differences between two potentially distinct facets of agency: responsibility and control. One contrasted the self-responsibility and selfcontrol cells, and the other contrasted the other-responsibility and othercontrol cells. No specific predictions were advanced for these contrasts. Finally, two contrasts were used to examine the relations between appraisals of unfairness and other-agency. The first contrasted the unfair cell with the 
Table V. Appraisal and Emotion Means for Investigation $1^{\text {h }}$

\begin{tabular}{lcccccc}
\hline & \multicolumn{6}{c}{ Condition } \\
\cline { 2 - 7 } & $\begin{array}{c}1 \\
\text { Self-res }^{a} \\
(24)^{f}\end{array}$ & $\begin{array}{c}2 \\
\text { Self-con }^{b} \\
(25)\end{array}$ & $\begin{array}{c}3 \\
\text { Other-res }^{c} \\
(25)\end{array}$ & $\begin{array}{c}4 \\
\text { Other-con }^{d} \\
(25)\end{array}$ & $\begin{array}{c}5 \\
\text { Sit-con }^{e} \\
(24)\end{array}$ & $\begin{array}{c}6 \\
\text { Unfair }^{(24)}\end{array}$ \\
\hline Appraisal scales & & & & & & \\
Human agency & 5.33 & 4.61 & 8.20 & 8.35 & 8.01 & 8.82 \\
Situational control & 5.04 & 4.33 & 4.28 & 3.60 & 7.96 & 3.38 \\
Certainty & 6.22 & 7.90 & 6.62 & 7.20 & 6.48 & 7.21 \\
Predictability & 4.28 & 6.83 & 4.92 & 6.08 & 4.52 & 3.88 \\
Attention & 6.62 & 8.08 & 7.06 & 7.32 & 7.11 & 6.21 \\
Pleasantness & 2.50 & 3.19 & 2.44 & 2.32 & 1.80 & 2.12 \\
Effort & 7.66 & 8.60 & 7.52 & 8.20 & 7.57 & 7.31 \\
Obstacle & 7.64 & 7.63 & 7.06 & 8.36 & 8.83 & 7.06 \\
Importance & 8.52 & 8.63 & 8.56 & 9.60 & 9.78 & 8.42 \\
Emotion scales & & & & & & \\
Anger & 4.63 & 4.39 & 5.76 & 5.83 & 4.96 & 6.47 \\
Guilt & 5.82 & 4.17 & 3.38 & 2.56 & 3.04 & 2.27 \\
Sadness & 5.96 & 5.13 & 5.28 & 5.64 & 6.91 & 4.75 \\
Fear & 5.40 & 4.75 & 5.42 & 5.00 & 5.74 & 3.21 \\
Resignation & 2.76 & 2.96 & 3.68 & 4.32 & 4.39 & 3.33 \\
Hope & 4.28 & 2.88 & 3.62 & 4.04 & 3.41 & 2.83 \\
Challenge & 3.13 & 3.57 & 2.97 & 3.41 & 2.57 & 3.15 \\
Surprise & 5.12 & 3.91 & 6.40 & 3.96 & 5.30 & 5.17 \\
Interest & 4.92 & 4.50 & 4.60 & 4.88 & 5.09 & 4.13 \\
\hline
\end{tabular}

${ }^{a}$ Self-responsibility.

${ }^{b}$ Self-control.

${ }^{\circ}$ Other-responsibility.

${ }^{d}$ Other-control.

'Situational-control.

${ }^{f}$ Numbers in parentheses are the cell $n$ 's.

${ }^{g}$ Challenge/pride.

${ }^{h}$ For the appraisal scales, scores increase in the direction of other-agency, and higher levels of situational control, certainty, predictability, attention to the situation, pleasantness, anticipated effort, and perceived obstacles, respectively. For all of the emotion scales, higher scores indicate increased levels of that emotion.

two other-agency cells, and the second contrasted the unfair cell with the two self-agency cells. We expected that the unfair cell would be very similar to the other-agency cells. That is, few differences were expected in the former contrast, while the latter one was expected to reveal differences similar to those of the self-agency versus other-agency contrast.

Each contrast was performed separately on the appraisal and emotion data. The analyses of the appraisal data served as manipulation checks to confirm that the appraisals varied across the cells in the intended ways. In addition, these analyses indicated the extent to which the cells differed systematically along appraisal dimensions that were not specifically manipulated in the experimental design. As will become apparent, several such differences were found, representing appraisal confounds that potentially ob- 
Table VI. $F$ Ratios for the Planned Comparisons in Investigation $1^{a}$

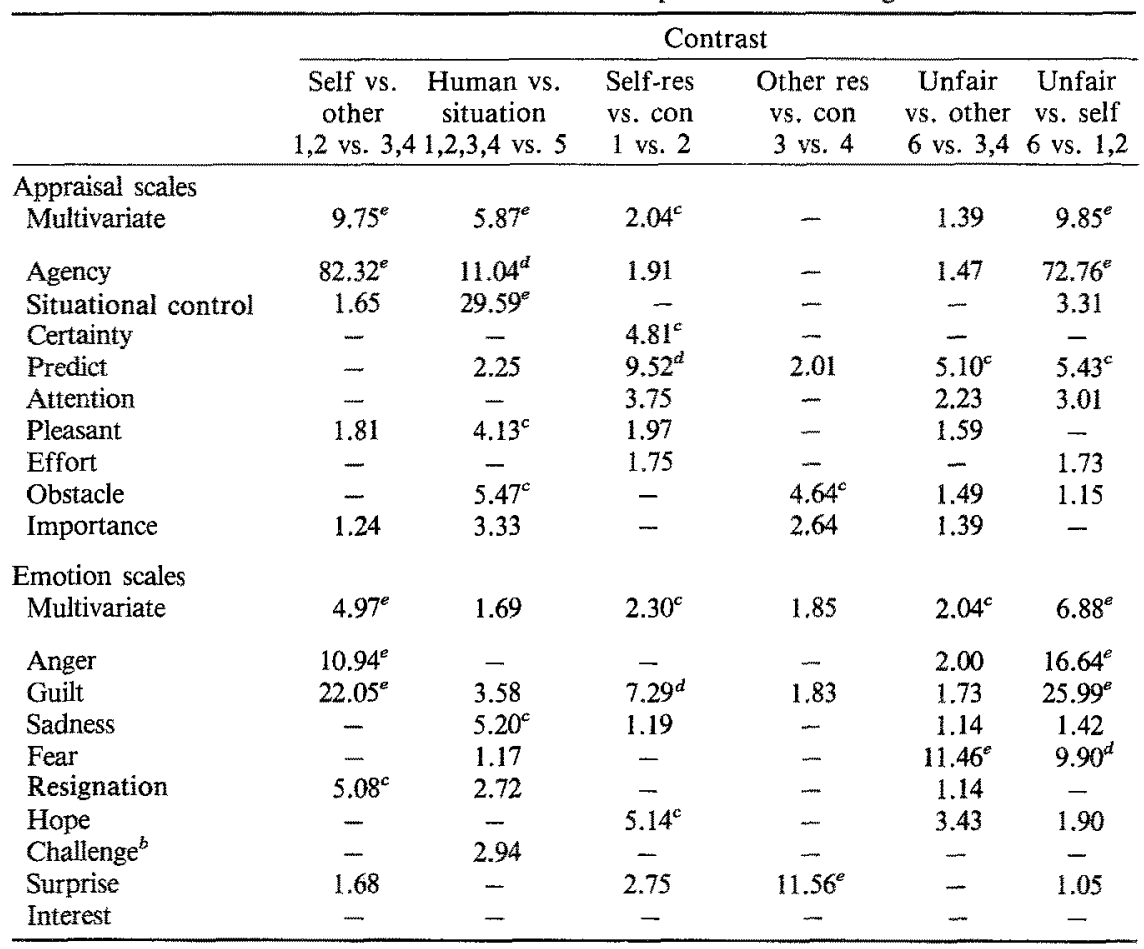

${ }^{a}$ All the multivariate $P$ s have 9 and $132 d f$. All of the univariate $F$ s have 1 and $140 \mathrm{df}$. For clarity of presentation, all $F s<1$ have been omitted.

${ }^{b}$ Challenge/pride.

${ }^{c} p<.05$.

${ }^{d} p<.01$.

${ }^{e} p<.001$.

scure the interpretation of the emotion contrast results. Therefore, in order to statistically control for these confounds, each of the emotion contrasts reported below (for all three investigations) was performed a second time with the scores along all of the appraisal dimensions except the one of direct interest entered as covariates. Because entering the covariates rarely affected the interpretation of the analyses, the results of the simple contrasts are reported below. However, in those cases where the two analyses yielded substantially different findings, the results of both are presented. The appraisal and emotion means for the six cells of this investigation are presented in Tablve $\mathrm{V}$, and the $F$ ratios associated with the planned comparisons are presented in Table VI.

Self-Agency Versus Other-Agency. The results of the contrast comparing self-agency with other-agency are presented in the first column of Table 
VI. Analysis of the appraisal data indicated that the cells differed, as intended, along the human agency dimension; Table $V$ reveals that the two self-agency cells were associated with clear appraisals of self-agency (combined $M=$ 4.96), and the two other-agency cells were associated with strong appraisals of other-agency (combined $M=8.28$ ). None of the other appraisal differences reached significance. Examination of the emotion data indicates that the self-agency and other-agency cells differed significantly in their associated levels of anger and guilt as predicted: Significantly higher levels of anger were reported in the two other-agency cells (combined $M=5.80$ ) than in the two self-agency cells (combined $M=4.51$ ), while, conversely, higher levels of guilt were experienced in the two self-agency cells (combined $M=$ 5.00 ) than in the two other-agency cells (combined $M=2.97$ ). Subjects also reported experiencing significantly higher levels of resignation under conditions of other-agency (combined $M=4.00$ ) than under conditions of selfagency (combined $M=2.86$ ).

Human Agency versus Situational Control. The results of the contrast comparing human agency and situational control appears in the second column of Table VI. Examination of Tables V and VI indicates that, as intended, appraisals of situational control were much stronger in the situational control cells $(M=7.96)$ than in the four human agency cells (combined $M$ $=4.30$ ). However, the appraisal of situational control was partially confounded with appraisals along other dimensions. Relative to the four human agency cells, the situations described in the situational control cell were appraised as involving more other-agency $(M=8.01$ versus combined $M$ $=6.62$ ), being less pleasant $(M=1.80$ versus combined $M=2.61)$, involving greater obstacles $(M=8.83$ versus combined $M=7.67)$, and tending to be more important ( $M=9.78$ versus combined $M=8.82$ ).

As predicted, subjects in the situational control cell reported experiencing higher levels of sadness ( $M=6.91$ versus combined $M=5.50$ ), and tended to experience lower levels of guilt ( $M=3.00$ versus combined $M=$ $3.98 ; F(1,140)=3.58, p=.06)$ than subjects in the four human agency conditions. However, contrary to predictions, the levels of anger reported in the situational control cell $(M=4.96)$ and the four human agency cells (combined $M=5.15$ ) did not differ significantly. The absence of this predicted difference was most likely due to the partial confound between appraisals of situational control and (human) other-agency in the situational control cell. When all of the appraisal scales except situational control were entered as covariates, the predicted difference in anger emerged; the adjusted level of anger in the situational control cell (adjusted $M=4.49$ ) was less than that in the combined four human agency cells (adjusted $M=5.39 ; F(1,132$ ) $=4.70, p<.05$ ).

However, entering these appraisal scales as covariates also removed the predicted difference in sadness between the situational control (adjusted $M$ 
$=6.19)$ and human agency conditions (adjusted combined $M=5.52 ; F(1$, $132)=1.09, p=.28)$. Follow-up analyses indicated that this result was due to the combined effects of appraisals of pleasantness, perceived obstacle, and importance (but, notably, not human agency), which were partially confounded with the appraisals of situational control. Entering all of the appraisal scales expect these three and situational control as covariates did not significantly alter the predicted difference (situational control $M=6.98$, combined human agency $M=5.42 ; F(1,135)=5.95, p<.05$ ); however, entering any one of the scales of pleasantness, perceived obstacle, or importance reduce the difference to a trend $\left(F^{\prime} \mathrm{s}(1,139)=2.59\right.$ to $2.86, p$ 's $=.09$ to .11). Entering just the situational control scale as a covariate essentially removed the predicted difference $(F(1,139)=1.12, p=.21)$. These results suggest that the high levels of sadness in the situational control condition may not have been due to situational control per se but may have been due instead to some closely related property of the situations described in that condition that was also related to appraisals of unpleasantness, importance, and high perceived obstacles.

Responsibility versus Control. The results of the two contrasts examining differences between appraisals of responsibility and control are presented in the third and fourth columns of Table VI. Although we sampled experiences associated with appraisals of responsibility and of control separately, the items intended to measure responsibility and control loaded on a single human agency dimension, as they had in our previous studies, indicating that appraisals of responsibility and control are generally correlated. Even though the presence of this relationship in our data minimizes the chances of observing possible differences in the emotions associated primarily with the two appraisals, the contrasts reveal some systematic differences.

First, subjects were generally more certain about their circumstances when they described experiences associated with appraisals of self-control than those of self-responsibility; relative to subjects in the self-responsibility cell, those in the self-control cell reported both that their situations were more predictable $(M=6.83$ versus $M=4.28)$, and that they were more certain about what was happening ( $M=7.90$ versus $M=6.22$ ). Under conditions of other-agency, subjects reported higher perceived obstacles when someone else was in control of the situation $(M=8.36)$ than when someone else was seen as responsible for the situation $(M=7.06)$. The emotion analyses indicated that in the self-responsibility condition subjects experienced higher levels of both guilt $(M=5.82$ versus $M=4.17)$ and hope $(M=4.28$ versus $M=2.88$ ) than those in the self-control condition. Situations associated with appraisals of other-responsibility yielded stronger feelings of surprise $(M=$ $6.40)$ than situations associated with appraisals of other-control $(M=3.96)$.

Unfairness versus Other-Agency and Self-Agency. The last two columns of Table VI present the results of the contrasts comparing the situations as- 
sociated with appraisals of unfairness with those associated with appraisals of other-agency and of self-agency, respectively. In general, these analyses support the hypothesis that for unpleasant experiences appraisals of otheragency and unfairness are functionally similar; very few differences emerged between the unfair and other-agency cells, and the differences between the unfair and self-agency cells largely mirrored those between the other- and self-agency cells. As in the other-agency cells, subjects in the unfair cell reported strong appraisals of other-agency $(M=8.82$ versus combined $M=4.97)$, high anger ( $M=6.47$ versus combined $M=4.51)$, and low guilt $(M=2.27$ versus combined $M=5.00$ ), relative to those in the self-agency cells. Interestingly, subjects in the unfair cell appraised their situations as less predic-

Table VII. Appraisal and Emotion Means and Planned Comparisons for Investigations 2 and $3^{h}$

\begin{tabular}{|c|c|c|c|c|c|c|}
\hline & \multicolumn{2}{|c|}{ Investigation 2} & \multirow[b]{2}{*}{$F^{\alpha}$} & \multicolumn{2}{|c|}{ Investigation 3} & \multirow[b]{2}{*}{$F^{b}$} \\
\hline & $\begin{array}{c}\text { Certain } \\
(24)^{c} \\
\end{array}$ & $\begin{array}{c}\text { Uncertain } \\
(24)\end{array}$ & & $\begin{array}{l}\text { Attend } \\
(22)\end{array}$ & $\begin{array}{c}\text { Shut out } \\
(24)\end{array}$ & \\
\hline $\begin{array}{l}\text { Appraisal scales } \\
\text { Multivariate }\end{array}$ & & & $3.01^{f}$ & & & $1.88^{e}$ \\
\hline $\begin{array}{l}\text { Human agency } \\
\text { Situational control } \\
\text { Certainty } \\
\text { Predictability } \\
\text { Attention } \\
\text { Pleasantness } \\
\text { Effort } \\
\text { Obstacle } \\
\text { Importance }\end{array}$ & $\begin{array}{l}6.53 \\
5.04 \\
8.27 \\
6.13 \\
6.56 \\
1.71 \\
7.85 \\
8.25 \\
9.46\end{array}$ & $\begin{array}{r}6.63 \\
6.17 \\
5.15 \\
4.25 \\
7.65 \\
1.83 \\
8.00 \\
7.73 \\
10.13\end{array}$ & $\begin{array}{c}-\overline{1} \\
1.36 \\
18.26^{8} \\
3.89 \\
2.26 \\
- \\
- \\
- \\
1.97\end{array}$ & $\begin{array}{l}5.95 \\
5.18 \\
6.52 \\
6.05 \\
8.07 \\
2.55 \\
7.91 \\
7.07 \\
9.68\end{array}$ & $\begin{array}{l}6.76 \\
6.33 \\
6.69 \\
4.88 \\
5.88 \\
2.08 \\
7.56 \\
8.44 \\
9.75\end{array}$ & $\begin{array}{c}1.56 \\
1.28 \\
- \\
1.88 \\
8.64^{f} \\
- \\
- \\
3.64 \\
-\end{array}$ \\
\hline $\begin{array}{l}\text { Emotional scales } \\
\text { Multivariate }\end{array}$ & & & - & & & - \\
\hline $\begin{array}{l}\text { Anger } \\
\text { Guilt } \\
\text { Sadness } \\
\text { Fear } \\
\text { Resignation } \\
\text { Hope } \\
\text { Challenge } \\
\text { Surprise } \\
\text { Interest }\end{array}$ & $\begin{array}{l}4.69 \\
3.94 \\
5.92 \\
5.08 \\
3.83 \\
3.02 \\
2.94 \\
4.83 \\
4.46\end{array}$ & $\begin{array}{l}3.90 \\
3.50 \\
6.33 \\
6.15 \\
2.92 \\
4.00 \\
2.89 \\
4.67 \\
5.92\end{array}$ & $\begin{array}{l}1.86 \\
- \\
- \\
2.54 \\
1.86 \\
2.57 \\
- \\
- \\
3.56\end{array}$ & $\begin{array}{l}4.17 \\
3.23 \\
6.05 \\
5.25 \\
3.27 \\
3.50 \\
3.12 \\
4.68 \\
5.64\end{array}$ & $\begin{array}{l}4.90 \\
3.27 \\
7.00 \\
6.06 \\
3.88 \\
3.31 \\
2.78 \\
5.21 \\
4.50\end{array}$ & $\begin{array}{l}1.26 \\
\overline{7} \\
1.71 \\
1.47 \\
- \\
- \\
- \\
1 . \overline{74}\end{array}$ \\
\hline
\end{tabular}

${ }^{a}$ In Investigation 2 all multivariate $F$ 's have $d f$ of $(9,38)$, and all univariate $F$ 's have $d f$ of $(1,46)$.

${ }^{b}$ In Investigation 3 all multivariate $F$ 's have $d f$ of $(9,36)$, and all univariate $F$ 's have $d f$ of $(1,44)$.

'Numbers in parentheses are the cell $n$ 's.

${ }^{d}$ Challenge/pride.

${ }^{\circ} p<.05$.

$f_{p}<.01$.

${ }^{8} p<.001$.

${ }^{h}$ For the appraisal scales, scores increase in the direction of other-agency, and higher levels of situational control, certainty, predictability, attention to the situation, pleasantness, anticipated effort, and perceived obstacles, respectively. For all of that emotion components, higher scores indicate increased levels of that emotion. For clarity of presentation, all $F$ 's $<1$ have been omitted. 
table ( $M=3.88$ versus combined $M=5.53$ ) but reported experiencing substantially less fear $(M=3.21$ versus combined $M=5.14)$ than subjects in any of human-agency cells. The finding for fear indicates that appraisals of legitimacy and agency are not equivalent. The reduced fear in the unfair cell is consistent with a proposal by Roseman (1984) that the appraisal of an unpleasant situation as undeserved confers a sense of moral strength, or power, upon the person (which in turn reduces the likelihood of being fearful) that is not necessarily conferred by appraising someone else as responsible for, and/or in control of, the situation.

\section{Investigation 2: Certainty}

The appraisal and emotion means for the certain and uncertain cells, as well as the results of the comparisons of these cells, are presented in Table VII. Examination of the appraisal data indicates that, as intended, the situations described in the certainty cell were associated with substantially stronger appraisals of certainty $(M=8.27)$ than those described in the uncertain cell $(M=5.15)$. In addition, higher levels of predictability were reported in the certain cell $(M=6.13)$ than in the uncertain cell $(M=4.25 ; F(1$, $46)=3.89, p=.05$ ). However, contrary to predictions, there were no reliable differences in the emotions experienced in the two cells. In particular, although the means are in the predicted direction, subjects in the uncertain cell did not report experiencing significantly more fear $(M=6.15)$ than subjects in the certain cell $(M=5.08 ; F(1,46)=2.54, p=.12)$.

\section{Investigation 3: Attentional Activity}

The appraisal and emotion means for the attend and shut out cells, as well as the results of the comparisons of these cells, are also presented in Table VII. As intended, the experiences reported in the attend cell were associated with substantially greater levels of attentional activity $(M=8.07)$ than those reported in the shut out cell $(M=5.88 ; F(1,44)=8.64, p<$ $.01)$. In addition, the experiences in the shut out cell tended to be associated with greater perceived obstacles $(M=8.44)$ than those in the attend cell $(M$ $=7.07 ; F(1,44)=3.64, p=.06)$. However, none of the emotions differed across the two conditions. One possible reason for this may be that the items intended to measure the two emotions expected to be most strongly affected by appraisals of attentional activity, disgust and frustration, were both subsumed by the anger scale, and thus, systematic effects due to attention may have canceled one another out. However, separate analyses of the frustration and disgust items provided no support for the predictions. In fact, con- 
trary to predictions, subjects reported experiencing significantly higher levels of frustration in the shut out cell $(M=7.50)$ than in the attend cell $(M=$ $5.13 ; F(1,44)=9.71, p<.01)$. Thus, for the unpleasant experiences examined in this investigation, selecting experiences based on differences in attention did not particularly distinguish the emotions that subjects reported experiencing.

\section{Single States or Mixed Emotions?}

One reason for defining the situations in terms of appraisals rather than in terms of particular emotions was to allow subjects to describe situations in which they had experienced mixed emotions. In order to assess the degree to which subjects reported feeling single or mixed emotions, we coded a subject as experiencing a particular emotion if his or her score for the appropriate emotion was at or above the scale midpoint (i.e., was 5 or greater). ${ }^{7}$ Using this criterion, we found that sadness $(N=174)$, fear $(N=133)$, interest $(N=133)$, surprise $(N=132)$, and anger $(N=118)$ were each experienced by roughly half or more of the subjects; resignation $(N=73)$, guilt $(N=$ 69 ), and hope $(N=65)$ were experienced by between a quarter and a third of the subjects; and challenge/pride $(N=40)$ was experienced by a sixth of the subjects.

Examination of the patterns of emotions experienced by individual subjects indicated substantial emotional blending. Only $15(6.3 \%)$ of the subjects were coded as experiencing a single, unblended emotion. The mean number of emotions reported by each subject was 3.90; almost two-thirds of the subjects $(N=153)$ were coded as experiencing three, four, or five emotions; and each of the unpleasant emotions (i.e., anger, fear, guilt, sadness, and resignation) combined with each of the other unpleasant emotions more than $25 \%$ of the time it was experienced (but not necessarily with all of them simultaneously).

\section{Patterns of Appraisal Characterizing the Individual Emotions}

The characteristic patterns of appraisal associated with the experience of the individual emotions were examined via simple correlations between

${ }^{7}$ This is the same conservative coding strategy we used previously (Smith \& Ellsworth, 1987). Obviously a less conservative criterion would have revealed even more blending than we report. Because the purpose of this analysis was to test for clear evidence of blending, we felt that a conservative strategy was called for. It should be noted that our choice of criterion affected only our qualitative description of the subjects' patterns of blending; it in no way affected the results of the regression analyses. 
the appraisals and the emotions, and a series of nine multiple regression analyses. In each of the latter, the scale score for a single emotion was regressed on the nine appraisal scales using the combined data from all three investigations $(N=240)$. The results of both the correlation and regression analyses are presented in Table VIII.

Both sets of analyses indicated highly characteristic patterns of appraisal for all of the emotions except hope. These patterns were largely consistent with our previous studies (Smith \& Ellsworth, 1985, 1987). In line with the results of Investigation 1, sadness, anger, and guilt were highly differentiated by appraisals along the two agency dimensions. Both the correlation and regression analyses indicated that sadness was reliably predicted by appraisals of situational control, guilt by the perception of oneself as agent, and anger by perceptions of some other person as agent. The experience of anger was further predicted by appraisals of extreme unpleasantness and substantial obstacles; the experience of sadness shared the appraisals of unpleasantness and obstacles, and was also predicted by the perceived importance of the situation; and guilt was associated with a desire to shut out what was happening in the situation.

Although the manipulation of certainty in Investigation 2 did not result in the predicted differences in fear, fear was associated with appraisals of uncertainty in both the correlation and regression analyses. It was also generally associated with appraisals of perceived obstacles and importance. The experience of resignation was predicted by appraisals that the situation had a predictable outcome, and that little effort was anticipated. The experience of challenge/pride was generally associated with appraisals of relative pleasantness, certainty about the situation, high levels of attentional activity, and high anticipated effort. Surprise was associated with appraisals that the situation was unpredictable and due to someone else. Finally, interest was generally associated with a desire to attend to a situation perceived as important.

\section{DISCUSSION}

A primary purpose of this study was to examine relations between appraisals and emotions in the context of emotional blending across a broad range of emotional situations. Our experimental design permitted us to examine the appraisal/emotion relations in two convergent ways; the results of both kinds of analysis indicated strong relations between our subjects' appraisals of their circumstances and the emotions they felt and, further, identified particular appraisals as being especially important in the experience of certain emotions. 


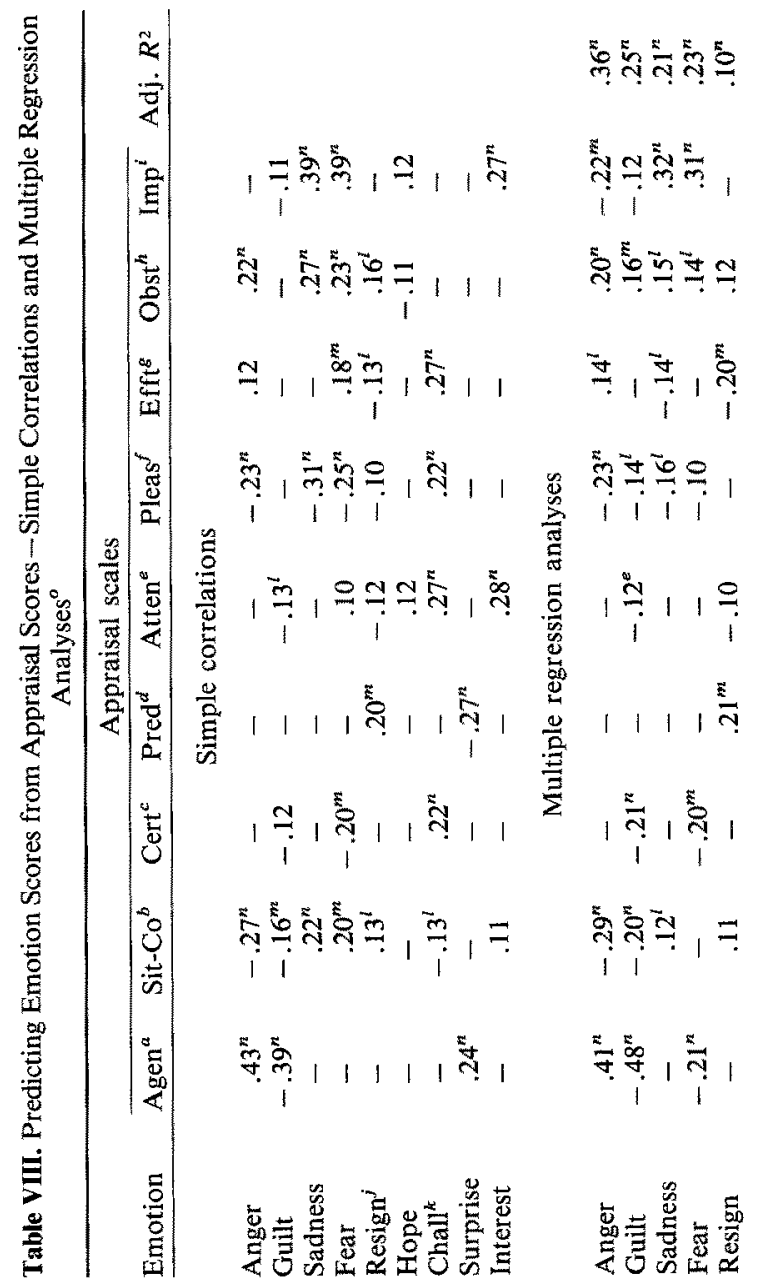




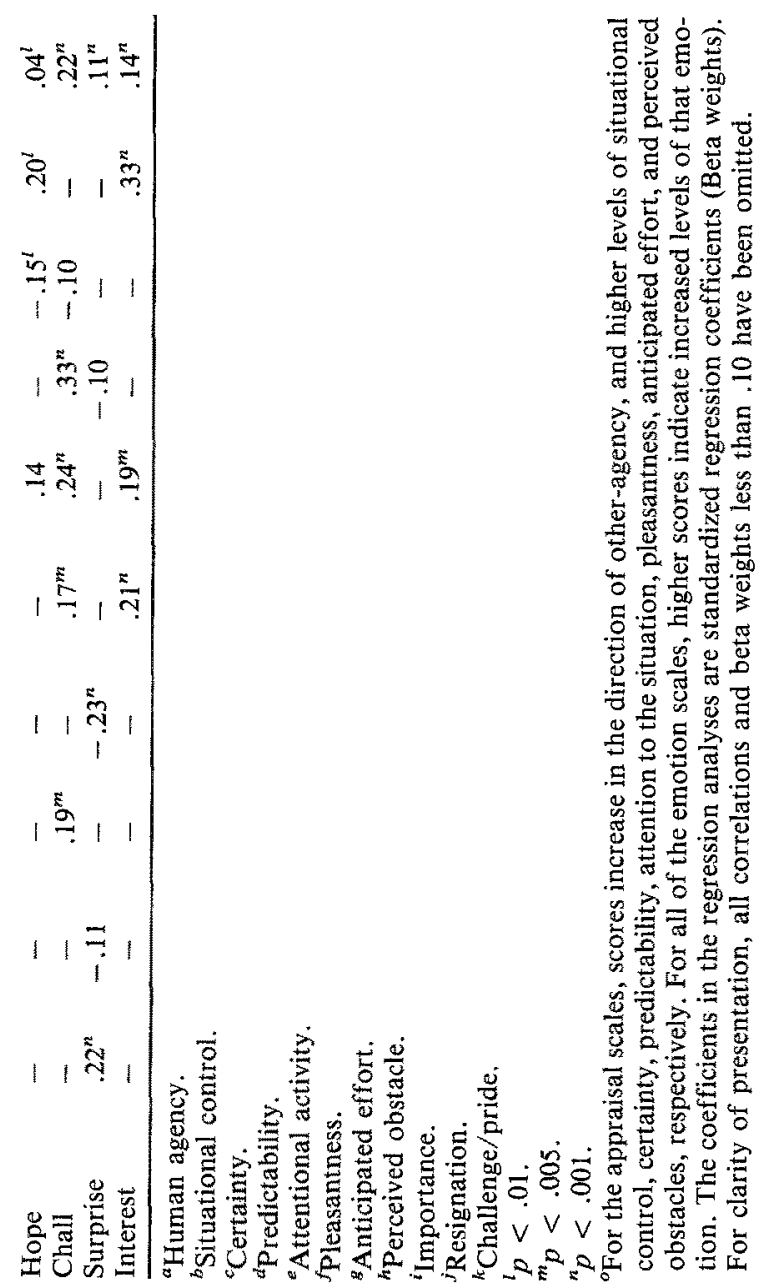


The results of Investigation 1 strongly affirmed the importance of agency in the differentiation of anger, guilt, and sadness. As predicted, the reported levels of anger were strongest when subjects described unpleasant situations in which they had attributed agency to someone else; guilt was highest when they described situations in which they had attributed agency to themselves. These results were not changed by statistically controlling the appraisals along other dimensions. In addition, subjects reported experiencing considerably more sadness when they attributed the unpleasant situation to impersonal circumstances than when they saw it as caused by some human agent (either oneself or someone else). However, the analyses of covariance indicated that as an alternative to situational control, this difference was attributable to the combined appraisals of unpleasantness, high obstacles, and importance. This result suggests that the increased sadness in the situational control condition may have been due to some appraisal closely related, but not identical, to situational control-a possibility that will be considered below.

As anticipated, the vast majority of subjects reported experiencing mixed emotions. Regression analyses of the patterns of appraisal associated with the experience of individual emotions in this context of blending indicated clear relations between the experience of specific emotions and particular patterns of appraisal, highly similar to those we observed previously (Smith \& Ellsworth, 1985, 1987). For instance, in line with the results of Investigation 1, the regression analyses clearly replicated the associations between sadness and appraisals of situational control, anger and appraisals of (human) other-agency, and guilt and appraisals of self-agency (and low attentional activity). In addition, further paralleling the findings of our original study, fear was predicted by appraisals of low certainty, surprise was associated with unpredictable situations appraised as due to someone else, interest was predicted by appraisals of high attentional activity, and challenge/pride was associated with high levels of both attention and certainty.

Nevertheless, the patterns of appraisal characterizing the individual emotions in this study were not identical to those observed in our original study of pure emotions (Smith \& Ellsworth, 1985). For example, in the original study anger and interest were both associated with moderate levels of certainty, and interest was further associated with moderate levels of both anticipated effort and situational control; guilt and fear were both associated with high levels of anticipated effort; sadness with appraisals of low attentional activity, moderately low certainty, and other-agency; surprise with appraisals of pleasantness, low effort, and high attention; and challenge and pride with appraisals of self-agency. None of these relations were observed in the present study.

These discrepancies support the hypothesis that not all of the appraisals typically associated with relatively pure instances of a given emotion are equal- 
ly important to the experience of that emotion. Thus, although the experience of sadness may typically involve a desire to shut out the situation, and although surprise may often be evoked under pleasant circumstances, the present findings indicate that it is quite possible to feel sad under conditions in which one wants to attend closely to the situation, or to be surprised by unexpected unpleasant events. Further, the dimensions reliably associated with particular emotions vary considerably from emotion to emotion. Thus, appraisals of agency are central to the experience of anger, guilt, and sadness but are not as important to the experience of the other emotions we examined. Appraisals of uncertainty are important in the experience of fear; high attentional activity is central to the experience of interest; effort, attention, and certainty are important to the experience of challenge/pride; and appraisals along the predictability dimension are important in the experience of resignation and surprise.

The fact that appraisals along any one dimension are more central to the experience of some emotions than of others may partially underlie the prevalence of emotional blending we and others (e.g., Folkman \& Lazarus, 1985; Izard, 1972; Schwartz \& Weinberger, 1980; Smith \& Ellsworth, 1987) have observed (see Scherer, 1984, for a similar proposal). Appraisals along certain dimensions are likely to be accompanied by the experience of a particular emotion, while other appraisals along other dimensions are likely to be accompanied by the experience of different emotions; emotional blending often may occur when appraisals central to different emotions, along different dimensions, cooccur. For instance, given unpleasant circumstances, we would expect that if the person appraises someone else as being responsible for the situation, then the person would likely feel angry. If the situation is also unexpected, then we would predict the person to feel both surprised and angry; conversely, if the person sees the situation as having been inevitable, then the anger might blend with a feeling of resignation. If the person feels uncertain about some aspect of the situation, then the anger might also blend with fear.

\section{Central Appraisals and Adaptive Functions}

Why do certain appraisals bear special relations to particular emotions? One theoretical reason is that such appraisals have important implications for the person's well-being, and that the emotions associated with these appraisals prepare the person to cope adaptively with these implications. Each emotion is hypothesized to serve a particular set of adaptive functions: Anger prepares and motives the person to attack and remove an irritant or obstacle; fear prepares and motivates the person to flee a danger; sadness serves as an appeal for support when the person is helpless; and guilt motivates 
the person to adhere to personal and social norms, and to behave in a responsible manner when faced with temptations to do otherwise (cf. Cannon, 1927, 1929; Izard, 1977; Lazarus, Kanner, \& Folkman, 1980; Plutchik, 1980). In this light, it is important to compare the appraisals we have found to be central to the experience of particular emotions with the functions those emotions are believed to serve. Our discussion deals only with unpleasant emotions because they were the focus of the study.

Anger-Perceived Obstacle and Other-Agency. Anger is the emotion of "fight" or attack (e.g., Cannon, 1929; Izard, 1977; Plutchik, 1980; Tomkins, 1963). The proposed function of anger is to prepare and motivate the person to remove an obstacle to his or her well-being from the environment. Thus, it makes sense that one of the appraisals central to anger is the perception of a goal-obstacle. Further, if anger-motivated attempts to remove the obstacle are to be successful, they should be directed at the source of irritation, and this source should be something that the person has the potential to influence and change. A human agent can be intimidated by angry behavior; against impersonal forces the same behavior is likely to be fruitless. Functionally, therefore, it makes considerable sense that the experience of anger is closely associated with the appraisal that an unpleasant situation is due to human agents other than oneself. This appraisal allows the person to direct his or her efforts toward a likely target, and, because this target is human, it is often possible for the person to influence and improve the situation.

Guilt-Perceived Obstacle and Self-Agency. Izard (1977) has proposed that the experience of guilt is important both in the development of one's conscience and in the maintenance of social order. Guilt serves to hold the person accountable for his or her actions. People who feel guilty may often castigate themselves (Wallington, 1973) and are often motivated to make reparation for any harm brought about by their behavior (e.g., Carlsmith \& Gross, 1969; Freedman, Wallington, \& Bless, 1967; Konečni, 1972; Regan, Williams, \& Sparling, 1972). Self-punishment reduces the likelihood that the unacceptable behavior will recur, and attempts to repair the damages tend to restore social harmony. Clearly, the conditions under which such guilt-motivated actions are most appropriate are when the person has done something to cause or perpetuate an unpleasant situation (i.e., has introduced goal-obstacles to the situation). Thus the functional relation between guilt and appraisals of self-agency (under unpleasant circumstances involving obstacles) is obvious.

Given this functional relation, the differences between appraisals of selfresponsibility and self-control in the experience of guilt, suggested by the results of Investigation 1, are intriguing. They suggest that it is not so much whether one can influence what is happening in an unpleasant situation, but whether one feels personally responsible or blameworthy, that is central to 
the experience of guilt. McGraw (1987) has similarly found attributions of self-blame to be much more closely related to guilt than attributions of selfcausality. Thus, techniques that minimize attributions of personal accountability are often effective in inducing people to perform behaviors they would otherwise find reprehensible (e.g., Milgram, 1974; Zimbardo, 1970); these techniques minimize the guilt associated with such actions. The current findings, combined with those of McGraw (1987), suggest that the conceptual distinction between responsibility and control should be maintained, even though the two are highly correlated.

Fear-Perceived Obstacles and Uncertainty? Fear is the emotion of "flight" (e.g., Cannon, 1929; Izard, 1977; Plutchik, 1980; Tomkins, 1963). Fear prepares and motivates the person to escape danger. Consistent with this function, fear is associated with appraisals of obstacles, indicating that the situation is one that seems harmful to one's well-being. In addition, fear is also associated with appraisals of uncertainty. However, this latter relation is not as clear as it might be: Although uncertainty was important both in the regression analyses and in our original study (Smith \& Ellsworth, 1985), the direct manipulation of certainty in Investigation 2 did not produce the predicted differences in fear.

We suspect that these discrepant results indicate that the certainty dimension needs to be refined. We have already distinguished between predictability of the outcome and certainty about the present situation. The regression results indicate that of the two, uncertainty about the present situation is more closely related to fear than the situation's predictability. However, not all kinds of uncertainty about the present situation are likely to be helpful in assessing whether it is dangerous. Instead, more specific appraisals, directly related to coping, such as uncertainty about the person's ability to escape or to deal with the threat, are most likely to be emotionally relevant. We suspect that uncertainty about coping is very important in the experience of fear and is captured to some extent by the certainty items on the appraisal questionnaire, but that it may not have been the type of certainty manipulated in Investigation 2 (subjects were asked to recall experiences when they "were (un)certain about what was happening in the situation").

Sadness-Perceived Obstacles and Situational Control? The results for sadness, like fear, were a little ambiguous. As predicted, subjects in the situational control condition (Investigation 1) reported experiencing more sadness than those in the other conditions, and in the regression analyses appraisals of situational control were reliable predictors of sadness. Nevertheless, the covariance analyses suggested that some dimension other than situational control may be central to experience of sadness, and a consideration of the theoretical functions served by sadness suggests a candidate for this appraisal. 
Sadness serves as an appeal for aid under conditions in which the person is helpless. The expression of distress is a signal that something is very wrong with the person's situation, and it is often effective in eliciting help and concern from others (Izard, 1977), which in turn often makes the harm or loss easier to bear and helps to reintegrate the individual into a social network (e.g., Cohen, Sherrod, \& Clark, 1986; Plutchik, 1980). However, this type of aid is expensive because it draws heavily upon the resources of others (cf. Coyne, 1976). Therefore, it is likely that sadness would be most effective as an appeal for help if it were largely limited to situations in which the person was unable to cope effectively with the situation. Thus, in contrast to anger or guilt, which can motivate the person to change the situation, sadness appears to be most functional under conditions in which the person feels helpless to do so.

Thus, the appraisal central to sadness, instead of being an attribution of the situation to impersonal circumstances, may be an appraisal that the situation is essentially uncontrollable. The relevant appraisal dimension, then, may be one of controllability, perhaps similar to the one discussed by Weiner and his colleagues (e.g., Russell, 1982; Russell \& McAuley, 1986; Weiner, 1985; Weiner, Graham, \& Chandler, 1982). We suspect that appraisals of situational control and controllability are highly correlated in adults, especially in our college student sample, and thus that situations appraised as due to impersonal circumstances are also appraised as less controllable than those appraised as due to a human agent (either oneself or someone else).

Resignation-Predictability and Low Effort. A feeling of resignation is likely to be experienced in aversive situations with predictable outcomes. Although the situation is unpleasant, the person does not anticipate expending much effort. This pattern (see Table VIII) suggests that resignation may "motivate" the person to avoid futile struggles against the inevitable, and to accept and adapt to permanent difficulties, or to endure more temporary unavoidable unpleasantness. Thus, although both sadness and resignation tend to occur under uncontrollable circumstances, they may serve different functions. Whereas sadness serves as an appeal for help, resignation may motivate acceptance of that which cannot be changed.

\section{Further Issues}

The Emotional Relevance of Attentional Activity. Like certainty in Investigation 2, the manipulation of attentional activity in Investigation 3 failed to produce the predicted emotional differences. One reason for this failure appears to be that our instructions did not lead subjects to recall situations strongly associated with the experience of boredom, or with distinct states of disgust or frustration - the three unpleasant emotions for which appraisals 
of attentional activity are likely to be important. Thus, whether or not appraisals along the attentional activity dimension are central to the experience of these three emotions remains an open question. Nevertheless, it is interesting that all of the emotions we observed were experienced at comparable levels in situations associated with either high or low attention. One possibility is that unpleasant experiences often involve considerable tension along the attention dimension. Although people may not want to think about unpleasant situations, they may have to pay close attention in order to find a way to escape or end the unpleasantness. Thus, as Investigation 3 suggests, many unpleasant emotions may be commonly associated with situations in which the person wants to attend to the situation, to avoid thinking about it, or both.

Hope. Of the nine emotions we examined, hope was least well predicted by the appraisal dimensions. We suspect that our relative failure to capture the patterns of appraisal associated with hope highlights an important limitation of the present study. In comparison with the other emotions, hope is not tightly bound to the person's present circumstances. Instead, hope is linked to expectations for the future; people are able to feel hopeful under extremely adverse conditions if they can maintain the belief that "in the end" things may work out (Abelson, 1983; Lazarus et al., 1980). The appraisal ratings in the present study were designed to provide us with a "still photograph" of the person's appraisals and emotions at a single time. This methodology was very successful in providing us with relatively clear views of the appraisals associated with a number of emotions, but it did not really assess the person's past expectations or beliefs about the future. The failure to capture the appraisals associated with hope emphasizes the need to examine the appraisal/emotion relations in a more dynamic context that more fully captures these aspects of the appraisal process.

\section{CONCLUSIONS AND FUTURE DIRECTIONS}

Working from a theoretical perspective that holds emotions to be adaptive products of our evolution, we have replicated previous observations of strong relations between people's appraisal of their circumstances and their emotional state. The data suggest that certain of these appraisals are central to the experience of particular emotions. Comparing these central appraisals to the hypothetical functions of their related emotions, we have argued that the appraisals and functions are consistent. In general, the central appraisals tend to ensure that the emotion will be experienced when it adaptively guides the person's coping efforts. Examination of the central appraisals for resignation, an emotion not typically considered in traditional theories, led us to propose plausible functions for this emotion that can be explored in future studies. Conversely, examination of the functions of fear and sadness 
led us to propose reconceptualizations of the appraisal dimensions central to these emotions. These results suggest the heuristic value of considering emotions from a functional perspective.

At the same time, however, we would be remiss if we did not join our predecessors and colleagues (e.g., Arnold, 1960; Izard, 1977; Lazarus, 1968; Tomkins, 1963) in admitting that emotional experiences are not always adaptive. People may often misperceive their situations and respond with "inappropriate" emotions, and even when the appraisals and emotional responses are "appropriate," the associated coping activities may often have very harmful consequences if they are not modulated by knowledge of social context and norms. Thus, if a person barges in front of you while you are standing in a long line at the grocery store, sternly suggesting that the person be fair and go to the end of the line might well be appropriate and adaptive, but physically attacking the person would not be. Nevertheless, we strongly believe that the emotional system is fundamentally designed to, and often does, serve adaptive functions.

Like any single study, this one leaves several questions unanswered and indicates new directions for future research. First, the appraisal view implies clear causal directions between appraisal and emotion: Appraisal determines emotion. However, this causality has yet to be clearly demonstrated. That our selection of experiences according to their appraisal characteristics produced predicted differences in emotional experience, combined with the finding that the central appraisals for particular emotions are related to the functions those emotions are believed to serve, increases the logical grounds for suspecting that appraisal leads to emotion. Nonetheless, as we have stated previously (Smith \& Ellsworth, 1987), it is still very important to demonstrate, through either experimental or longitudinal analysis, that changes in a person's appraisal of his or her circumstances produce systematic changes in that person's emotional state. Also, although our theory is a theory of the role of situational appraisals in the actual experience of emotions, much of our work (though not all, cf. Ellsworth \& Smith, 1987; Smith, 1987; Smith \& Ellsworth, 1987) has used retrospective verbal reports and thus could conceivably relate more to ideas about emotions than to emotions themselves.

Further, the present findings indicate that it is premature to conclude that the dimensional structure we have outlined here is the "correct" one. To the contrary, our results indicate several areas in which the dimensional structure needs to be further refined and elaborated (e.g., potential differences between appraisals of responsibility and control, and between situational control and controllability, need to be investigated, and the certainty dimension needs to be better defined).

Finally, we believe that one of the most important new directions for future research is to examine the appraisal/emotion relations in the context of the behaviors they motivate and produce. The relations between emotions 
and modes of coping need to be better delineated. In this regard, we feel that it is especially important to examine appraisal/emotion/coping relations in the context of emotional blending. We suspect that the coping tendencies motivated by individual emotions interact in emotional blends to produce even more adaptive coping than would be produced by single emotions in isolation. For instance, fear of retaliation (or of social sanctions, or of guilt) may often prevent us from assaulting those who anger us and, instead, may motivate us to modulate the anger, and to seek less overtly aggressive, more socially acceptable ways of eliminating the problem. In any case, we feel that it is of vital importance to bring an examination of action tendencies (Frijda, 1987) and coping activities (e.g., Folkman \& Lazarus, 1980; Folkman, Lazarus, Dunkel-Schetter, DeLongis, \& Gruen, 1986) into the study of appraisal/emotion relations. We believe that it is through such analyses that we will begin to firmly grasp the nature of the functions - and the failings - of human emotions.

\section{REFERENCES}

Abelson, R. P. (1983). Whatever became of consistency theory? Personality and Social Psychology Bulletin, 9, 37-54.

Arnold, M. B. (1960). Emotion and personality (2 vols.). New York: Columbia University Press.

Cannon, W. B. (1927). The James-Lange theory of emotion: A critical examination and an alternative theory. American Journal of Psychology, 39, 106-124.

Cannon, W. B. (1929). Bodily changes in pain, hunger, fear, and rage (2nd ed.). New York: Appleton-Century.

Carlsmith, J. M., \& Gross, A. E. (1969). Some effects of guilt on compliance. Journal of Personality and Social Psychology, 11, 232-239.

Cohen, S., Sherrod, D. R., \& Clark, M. S. (1986). Social skills and the stress protective role of social support. Journal of Personality and Social Psychology, 50, 963-973.

Coyne, J. (1976). Toward an interactional description of depression. Psychiatry, 39, 28-40.

D'Andrade, R. G. (1981). The cultural part of cognition. Cognitive Science, 5, 179-195.

Darwin, C. (1965). The expression of the emotions in man and animals. Chicago: University of Chicago Press. (Original work published 1872)

Ellsworth, P. C., \& Smith, C. A. (1987). Models and memories of emotion: A comparison of their associated appraisals and facial expressions. Unpublished manuscript, Stanford University.

Folkman, S., \& Lazarus, R. S. (1980). An analysis of coping in a middle-aged community sample. Journal of Health and Social Behavior, 21, 219-239.

Folkman, S., \& Lazarus, R. S. (1985). If it changes it must be a process: Study of emotion and coping during three stages of a college examination. Journal of Personality and Social Psychology, 48, 150-170.

Folkman, S., Lazarus, R. S., Dunkel-Schetter, C., DeLongis, A., \& Gruen, R. J. (1986). The dynamics of a stressful encounter: Cognitive appraisal, coping, and encounter outcomes. Journal of Personality and Social Psychology, 50, 992-1003.

Freedman, J. L., Wallington, S. A., \& Bless, E. (1967). Compliance without pressure: The effect of guilt. Journal of Personality and Social Psychology, 7, 117-124.

Frijda, N. H., (1986). The emotions. Cambridge: Cambridge University Press.

Frijda, N. H. (1987). Emotion, cognitive structure, and action tendency. Cognition and Emotion, $1,115-143$. 
Izard, C. E. (1972). Patterns of emotions. New York: Academic Press.

Izard, C. E. (1977). Human emotions. New York: Plenum.

James, W. (1950). The principles of psychology (Vol. 2). New York: Dover. (Original work published 1890)

Konečni, V. J. (1972). Some effects of guilt on compliance: A field replication. Journal of Personality and Social Psychology, 23, 30-32.

Lazarus, R. S. (1968). Emotions and adaptation: Conceptual and empirical relations. In W. J. Arnold (Ed.), Nebraska symposium on motivation, 1968 (pp. 175-266). Lincoln: University of Nebraska Press.

Lazarus, R. S. (1982). Thoughts on the relations between emotion and cognition. American Psychologist, 37, 1019-1024.

Lazarus, R. S., Kanner, A. D., \& Folkman, S. (1980). Emotions: A cognitive-phenomenological analysis. In R. Plutchik \& $\mathrm{H}$. Kellerman (Eds.), Emotion: Theory, research, and experience: Vol. 1. Theories of emotion (pp. 189-217). New York: Academic Press.

Leeper, R. W. (1948). A motivational theory of emotion to replace "emotion as disorganized response." Psychological Review, 55, 5-21.

McGraw, K. M. (1987). Guilt following transgression: An attribution of responsibility approach. Journal of Personality and Social Psychology, 53, 247-256.

Milgram, S. (1974). Obedience to authority. New York: Harper \& Row.

Plutchik, R. (1980). Emotion: A psychoevolutionary synthesis. New York: Harper \& Row.

Regan, D. T., Williams, M., \& Sparling, S. (1972). Voluntary expiation of guilt: A field experiment. Journal of Personality and Social Psychology, 24, 42-45.

Roseman, I. J. (1984). Cognitive determinants of emotions: A structural theory, in P. Shaver (Ed.), Review of personality and social psychology: Vol. 5, Emotions, relationships, and health (pp. 11-36). Beverly Hills: Sage.

Rosenthal, R., \& Rosnow, R. L. (1985). Contrast analysis: Focused comparisons in the analysis of variance. New York: Cambridge University Press.

Russell, D. (1982). The Causal Dimension Scale; A measure of how individuals perceive causes. Journal of Personality and Social Psychology, 42, 1137-1145.

Russell, D., \& McAuley, E. (1986). Causal attributions, causal dimensions, and affective reactions to success and failure. Journal of Personality and Social Psychology, 50, 1174-1185.

Scherer, K. R. (1984). On the nature and function of emotion: A component process approach. In K. R. Scherer \& P. Ekman (Eds.), Approaches to emotion (pp. 293-317). Hillsdale, $\mathrm{NJ}$ : Erlbaum.

Schwartz, G. E., \& Weinberger, D. A. (1980). Patterns of emotional responses to affective situations: Relations among happiness, sadness, anger, fear, depression, and anxiety. Motivation and Emotion, 4, 175-191.

Smith, C. A. (1987). The informational structure of the facial expression of emotion. Dissertation Abstracts International, 47, 4002B. (University Microfilms No. 87-00,820)

Smith, C. A., \& Ellsworth, P. C. (1985). Patterns of cognitive appraisal in emotion. Journal of Personality and Social Psychology, 48, 813-838.

Smith, C. A., \& Ellsworth, P. C. (1987). Patterns of appraisal and emotion related to taking an exam. Journal of Personality and Social Psychology, 52, 475-488.

Tomkins, S. S. (1963). Affect, imagery, consciousness: Vol. 2. The negative affects. New York: Springer.

Wallington, S. A. (1973). Consequences of transgression: Self-punishment and depression. Journal of Personality and Social Psychology, 28, 1-7.

Weiner, B. (1985). An attributional theory of achievement motivation and emotion. Psychological Review, 92, 548-573.

Weiner, B., Graham, S., \& Chandler, C. (1982). Pity, anger, and guilt, Personality and Social Psychology Bulletin, 8, 226-232.

Zimbardo, P. G. (1970). The human choice: Individuation, reason and order versus deindividuation, impulse and chaos. In N. J. Arnold \& D. Levine (Eds.), Nebraska symposium on motivation (pp. 237-307). Lincoln: University of Nebraska Press. 